\title{
INFLUÊNCIA DA TAXA DE CÂMBIO SOBRE A INFLAÇÃO NA ECONOMIA BRASILEIRA (1999-2015)
}

\author{
Paulo Rogério Alves Brene, Universidade Estadual do Norte do Paraná - UENP. \\ paulobrene@uenp.edu.br \\ Giseli Teotonio Alvarenga, Universidade Estadual do Norte do Paraná - UENP. \\ giseleteotonio.al@gmail.com \\ Alessandro Garcia Bernardelli, Universidade Estadual do Norte do Paraná - UENP. \\ alessandroagb@hotmail.com \\ Ana Maria Machado Caravieri, Universidade Estadual do Norte do Paraná - UENP. \\ anacaravieri@gmail.com
}

\section{RESUMO}

Este trabalho visa verificar a influência da taxa de câmbio sobre a inflação na economia brasileira no período de 1999 a 2015. Para tanto realizou-se uma investigação bibliográfica e após coleta dos dados de inflação e câmbio foi feita uma análise para verificar a correlação entre eles. Nesse sentido utilizou-se os coeficientes de correlação de Pearson e Spearman. Como resultado observa-se que a taxa de câmbio em relação ao IPCA possui uma correlação moderada nos primeiros meses, o índice de Pearson encontrado entre eles é de 0,17 a 0,43 (com significância), já a correlação em relação ao IGP-DI é uma correlação fraca desde o segundo mês, o índice encontrado entre eles é de 0,16 a 0,35 (também com significância). Já para os índices de Spearman, a hipótese $\mathrm{H}_{0}$ (ausência de associação entre as variáveis) foi rejeitada. Nesse sentido a pesquisa mostra que no caso brasileiro, a taxa de câmbio tem uma influência relevante sobre a inflação. Por fim destaca-se que a taxa de câmbio (seja comercial ou nominal) influenciam o IPCA até o sétimo mês, em outras palavras, a título de exemplo, a taxa de câmbio de janeiro tem correlação com o IPCA de julho (do mesmo ano), por sua vez para o IGP-DI essa influência vai até o quarto mês.

Palavras-chave: Inflação, Câmbio, Índices de Correlação, Economia brasileira, Metas para inflação.

Data de recebimento: $30 / 08 / 2020$

Data do aceite de publicação: 15/04/2021

Data da publicação: 30/04/2021 


\title{
INFLUÊNCIA DA TAXA DE CÂMBIO SOBRE A INFLAÇÃO NA ECONOMIA BRASILEIRA (1999-2015)
}

\section{INFLUENCE OF THE EXCHANGE RATE ON INFLATION IN THE BRAZILIAN ECONOMY (1999-2015)}

\author{
Paulo Rogério Alves Brene, Universidade Estadual do Norte do Paraná - UENP. \\ paulobrene@uenp.edu.br \\ Giseli Teotonio Alvarenga, Universidade Estadual do Norte do Paraná - UENP. \\ giseleteotonio.al@gmail.com \\ Alessandro Garcia Bernardelli, Universidade Estadual do Norte do Paraná - UENP. \\ alessandroagb@hotmail.com \\ Ana Maria Machado Caravieri, Universidade Estadual do Norte do Paraná - UENP. \\ anacaravieri@gmail.com
}

\begin{abstract}
This job aims to verify what the influence of the exchange rate over the inflation in the Brazilian economy is in a period that is between 1999 and 2015. For this purpose a bibliographical investigation was carried out and after the data collection of inflation and exchange, an analysis was made to verify the correlation between them. Therefore, Pearson e Spearman correlation coefficients have been used. As a result, it is observed that the exchange rate in relation to IPCA has a moderate correlation in the first months, Pearson index found between them is from 0,08 to 0,431 , on the other hand the correlation in relation to IGP-DI is a week correlation since the second month but the index found between them is from 0,05 to 0,352. About Spearman indexes, the hypothesis $\mathrm{H}_{0}$ (absence of association between the variables) has been rejected. The survey shows that in the Brazilians case, the exchange rate has a relevant influence on the inflation. Finally, it should be noted that the exchange rate (either commercial or nominal) influences the IPCA up to the seventh month, in other words, as an example, the January exchange rate is correlated with the IPCA of July (of the same year ), in turn for the IGPDI this influence extends to the fourth month.
\end{abstract}

Key words: Inflation, Exchange, Correlation Indexes, Brazilian economy, Targets for inflation.

\section{INTRODUÇÃO}

O Brasil tem, ao longo de sua história econômica, uma característica marcante que é a ocorrência de períodos de alta inflação. A implantação do Plano Real em 1994 foi uma política de estabilização bem-sucedida, por meio desse plano foi possível remover a memória inflacionária acumulada pelas políticas econômicas que foram utilizadas anteriormente. Em 1999 foi implantado o regime de metas para inflação e o regime cambial foi alterado para um regime flutuante com a intervenção do Banco Central em alguns períodos (dirty floating), ou a aplicação de bandas cambiais quando necessário. Assim, a taxa de câmbio ganhou maior importância na determinação dos preços domésticos. Dessa forma, é importante observar que os repasses da variação da taxa de câmbio passaram a transmitir seus choques para os índices de preços domésticos de forma mais intensa, provocando variações na inflação.

Uma das preocupações das autoridades monetárias é o acompanhamento das variações cambiais e a análise do impacto destas alterações nos preços da economia. Vários artigos como Betts e Devereux (1996), Pollard e Couglhlin (2005) e Campa e Goldberg (2002), analisam a relação entre a taxa de câmbio e a política monetária, tendo 


\section{INFLUÊNCIA DA TAXA DE CÂMBIO SOBRE A INFLAÇÃO NA ECONOMIA BRASILEIRA (1999-2015)}

assim vários modelos, na literatura econômica como Goldfajn e Werlang (2000), Cunningham e Haldane (2000) e Gagnon (2007), que mensuram o quanto um aumento ou uma redução da taxa de câmbio faz com que a inflação aumente ou tenha uma queda e cada autor utiliza o que melhor atende suas necessidades (modelos de equilíbrio geral, análise de regressão entre outros).

Assim, o presente estudo, seguindo os trabalhos citados (contudo por outra perspectiva metodológica), tem como problema de pesquisa a pergunta que segue: qual a correlação entre o efeito das variações cambiais e os índices inflacionários? Nesse sentido, o objetivo deste artigo é mensurar a correlação entre a variação cambial e a inflação na economia brasileira no período de 1999 a 2015, período este em que se iniciou o regime de metas para a inflação, assim como, período em que o câmbio passou a ser flutuante. Para tanto pretende-se realizar uma revisão de literatura relativa à inflação e taxa de câmbio no Brasil, e verificar o repasse cambial para a inflação por meio da análise da correlação dos dados - destacando a defasagem temporal nas análises.

Para este fim, os dados utilizados são de periodização mensal, sendo eles o Índice de Preços ao Consumidor Amplo (IPCA), que é o índice oficial do governo, o Índice Geral de Preços - Disponibilidade Interna (IGP-DI), que serviu como indicador oficial de inflação até 1985, a taxa de câmbio comercial e a taxa de câmbio nominal. Os dados analisados neste artigo serão medidos por meio dos coeficientes de correlação de Pearson e Spearman.

A organização desse artigo segue da seguinte forma: primeira seção contendo a introdução, na seção 2 será abordado os conceitos sobre taxa de câmbio e inflação. Na seção 3 apresentam-se os dados dos índices utilizados para a inflação e câmbio e a metodologia de cálculo dos índices de correlação de Pearson e de Spearman. A análise e comparação dos dados referentes ao período de 1999 a 2015 encontram-se na quarta seção. Por fim, as considerações finais na seção 5.

\section{REFERÊNCIAL TEÓRICO}

Ao analisar a economia brasileira observa-se que a inflação tem sido um dos temas mais discutidos. De acordo com Vasconcellos e Garcia (2011, p. 262) a inflação é um processo de "(...) aumento contínuo e generalizado no índice de preços (...)". Dentro desse conceito, segundo Lanzana (2010), deve-se levar em consideração que a inflação é um processo e não deve ser confundido com um fato isolado, pois, os aumentos de preços são contínuos e não esporádicos. Por sua vez para Furtado (2012), a inflação também pode ser definida no sentido de perda do valor real da moeda. Assim, para Vasconcellos e Garcia (2011), uma forma de se estudar a questão inflacionária é distinguir os tipos de inflação existentes. Nessa linha, segundo Lanzana (2010), são três os tipos básicos de inflação: inflação de demanda, inflação de custos e inflação inercial.

A inflação de demanda, de acordo com Lanzana (2010, p. 105), “(...) é causada por um excesso de procura em relação à oferta disponível (...)". A inflação de custos, para Vasconcellos e Garcia (2011), está associada a uma inflação de oferta. A demanda continua a mesma, mas os custos de alguns fatores importantes aumentam e em consequência ocorre um aumento nos preços de mercado. Ainda segundo Vasconcellos e Garcia (2011), a inflação inercial é um processo de realimentação dos preços, ou seja, a inflação atual sucede a inflação passada e está associada aos mecanismos de indexação da economia.

Ao discutir sobre o efeito da política cambial sobre os índices inflacionários é necessário entender alguns conceitos. $\mathrm{O}$ primeiro deles está relacionado à própria taxa de câmbio. Nesse sentido, conforme o Banco Central do Brasil (BACEN, 2016) taxa de 


\section{INFLUÊNCIA DA TAXA DE CÂMBIO SOBRE A INFLAÇÃO NA ECONOMIA BRASILEIRA (1999-2015)}

câmbio é o preço de uma moeda estrangeira convertido em moeda nacional. Na mesma linha, de acordo com Lanzana (2010, p.72), “(..) a taxa de câmbio é um preço fundamental da economia, porque afeta a situação do setor externo, a inflação, o crescimento da produção e assim por diante (...)". Segundo Bresser-Pereira (2007), a taxa de câmbio é o preço mais estratégico no desenvolvimento econômico, pois além de ter implicações diretas na estabilidade macroeconômica implica também na poupança e no investimento.

$\mathrm{Na}$ sequência, outro conceito importante refere-se aos sistemas cambiais, conhecidos também como regimes cambiais. Conforme Lopes e Vasconcellos (2014), os sistemas cambiais que podem ser adotados são: câmbio fixo, bandas cambiais, câmbio flutuante e flutuação suja. Segundo Lanzana (2010, p.73) no regime de taxas fixas de câmbio "(...) o valor da moeda estrangeira é determinado pelo governo e não se altera (...)". Nessa linha, Vasconcellos e Garcia (2011) aponta que o Banco Central é obrigado a disponibilizar as reservas cambiais. O sistema de câmbio fixo é normalmente adotado por países que possuem taxas de inflação elevadas, pois, segundo Lanzana (2010), esses países encontram no câmbio fixo uma forma de eliminar a inflação já que os preços dos produtos importados param de subir. Para que esse sistema seja eficiente no combate à inflação, as políticas fiscal e monetária devem ser conduzidas adequadamente.

Dentro do regime de câmbio fixo existe o sistema de bandas cambiais, de acordo com Vasconcellos e Garcia (2011), o governo fixa limites superior e inferior chamado bandas, dentro das quais as taxas de câmbio podem flutuar, contudo considerado câmbio fixo devido aos limites de variação serem fixados. Neste sistema cambial o Banco Central compra ou vende divisas para que a cotação se mantenha dentro das bandas. No regime de taxas flutuantes ou flexíveis, segundo Lanzana (2010), “(...) o valor da moeda estrangeira é determinado pelas forças livres de mercado (...)". De acordo com Vasconcellos e Garcia (2011) é o mercado quem determina a taxa de câmbio, o Banco Central não tem obrigação de disponibilizar reservas cambiais. Esse sistema cambial é bastante volátil, pois há movimentos bruscos de entrada e/ou saída de dólares e podem ocorrer grandes desvalorizações cambiais que consequentemente impactarão na taxa de inflação do país.

Dentro desse sistema de câmbio flutuante existe o sistema conhecido como "flutuação suja" (dirty floating). De acordo com Lanzana (2010) nesse sistema, o câmbio flutua livremente, mas o Banco Central impõe certos limites os quais não comunica ao mercado. Para Vasconcellos e Garcia (2011), se o Banco Central perceber que a taxa de câmbio está muito alta e pressionando as taxas de inflação, o Banco Central vende dólares diminuindo sua cotação, fazendo o contrário quando a cotação estiver muito baixa. Pela característica mercadológica esse regime cambial é adotado pela maioria dos países.

De acordo com Maciel (2006) e Menezes e Fernandez (2012), os efeitos dos movimentos cambiais em relação às alterações nos índices de preços dos bens para os consumidores, nos investimentos, na quantidade de comércio e nos preços das importações e exportações é conhecido na literatura econômica como pass-through. Em outras palavras, é o quanto um aumento ou uma redução da taxa de câmbio faz com que a inflação aumente ou tenha uma queda. Segundo Maciel (2006) vários fatores afetam o grau desse repasse cambial, mas em geral, quanto maior forem a abertura da economia, o aquecimento da demanda doméstica, a participação de insumos importados na produção do bem, e maior o desvio da taxa de câmbio de sua taxa de equilíbrio, maior será o grau do repasse.

Goldfajn e Werlang (2000) demonstram em seu trabalho, que o pass-through aumenta ao longo do período. Com o passar do tempo, esse efeito tende a se ampliar na economia e o grau de transmissão é maior em economias emergentes. Ainda de acordo 


\section{INFLUÊNCIA DA TAXA DE CÂMBIO SOBRE A INFLAÇÃO NA ECONOMIA BRASILEIRA (1999-2015)}

com os autores, quanto mais estável o país menor o seu pass-through, afirmam também que para o caso brasileiro, o pass-through chega no seu valor máximo em 12 meses. Por fim, segundo Menezes e Fernandez (2012), o pass-through é bastante relevante quando se trata de estudos de economias abertas sob um regime de câmbio flutuante.

\section{METODOLOGIA}

Segundo Figueiredo e Gouvea (2011), as autoridades monetárias têm como uma de suas preocupações o acompanhamento das variações no câmbio, e da análise do impacto destas alterações nos diversos preços da economia. Vários artigos analisam a relação entre a taxa de câmbio e a política monetária como, por exemplo, Betts e Devereux (1996) onde, em seu estudo, dizem que o efeito de bem estar da política monetária está relacionado ao grau do repasse cambial da economia, e Werlang e Goldfajn (2000) que dizem que o grau de repasse cambial para os preços está associado ao erro de previsão da inflação, demonstrando se o efeito da política monetária está dando resultado.

Outros artigos tem o enfoque no comportamento do repasse cambial em nível industrial, a exemplo de Pollard e Couglhlin (2005) e Campa e Goldberg (2002), que demonstram que o repasse cambial varia entre indústrias, e a melhor análise do grau de pass-through deve ser feita não entre países e, sim, entre indústrias. Alguns artigos mostram a tendência de redução do repasse cambial para os conjuntos de preços domésticos, tanto em países industrializados quanto em países emergentes, exemplos são Cunningham e Haldane (2000), Goldfajn e Werlang (2000), Gagnon (2007) e Burnstein, Eichenbaum e Rebelo (2005) que demonstram, em seus estudos, que economias abertas, após significantes desvalorizações cambiais, sofrem baixa pressão inflacionária.

Existem vários modelos na literatura econômica, como os citados, que mensuram o grau de pass-through, ou seja, o quanto um aumento, ou uma redução da taxa de câmbio, faz com que a inflação se eleve ou tenha uma queda. Cada autor utiliza ferramentas que melhor atende as suas necessidades. Nesse trabalho será utilizado a correlação entre o câmbio e os preços ao consumidor aplicado a economia brasileira. O período escolhido para ser estudado é de 1999 a 2015, período em que se iniciou o regime de metas para a inflação, até os dias atuais, período esse também em que o câmbio passa a ser flutuante.

Segundo Figueiredo e Gouveia (2011), estudos mostram que as variações na taxa de câmbio raramente se refletem imediatamente, ou inteiramente, nos preços ao consumidor. Belaich (2003) argumenta que para analisar o grau de repasse cambial para os preços domésticos, primeiro é necessário decidir qual indicador do nível de preços é relevante. Para a verificação do impacto do repasse cambial sobre os preços ao consumidor, assim para fins deste trabalho serão utilizados dados de periodização mensal, sendo eles o Índice de Preços ao Consumidor Amplo (IPCA) por ser a medida de inflação oficial do governo, e é um índice importante para determinar a política monetária.

O Índice Geral dos Preços - Disponibilidade Interna (IGP-DI) foi escolhido por ser uma medida mais precisa da inflação, e é útil para avaliar o grau do repasse cambial em diferentes setores da economia por englobar três outros índices nacionais. Será utilizada a taxa de câmbio nominal, por ser a taxa divulgada pelas instituições financeiras e também a taxa de câmbio comercial, preço de venda, que demonstra as operações de câmbio do mercado.

O primeiro passo para a análise dos dados foi a construção do Gráfico 1, que proporciona uma visualização do relacionamento entre a inflação e a taxa de câmbio. A taxa de câmbio comercial, a taxa de câmbio nominal e o IGP-DI possuem, de acordo com o Gráfico2, o mesmo comportamento, o IPCA tem um comportamento levemente 


\section{INFLUÊNCIA DA TAXA DE CÂMBIO SOBRE A INFLAÇÃO NA ECONOMIA BRASILEIRA (1999-2015)}

diferente, mas, seguindo a mesma tendência. $\mathrm{O}$ gráfico indica ainda que existe uma relação positiva entre as variáveis, pois, quando há um crescimento na taxa de câmbio, observa-se também, um crescimento nos índices inflacionários. Segundo Furtado (2012), "(...) o reajuste da taxa de câmbio obedece, em princípio, ao diferencial entre inflação doméstica e a inflação externa".

Gráfico 1. Comportamento da Inflação e do Câmbio no Período de 1999 a 2015.

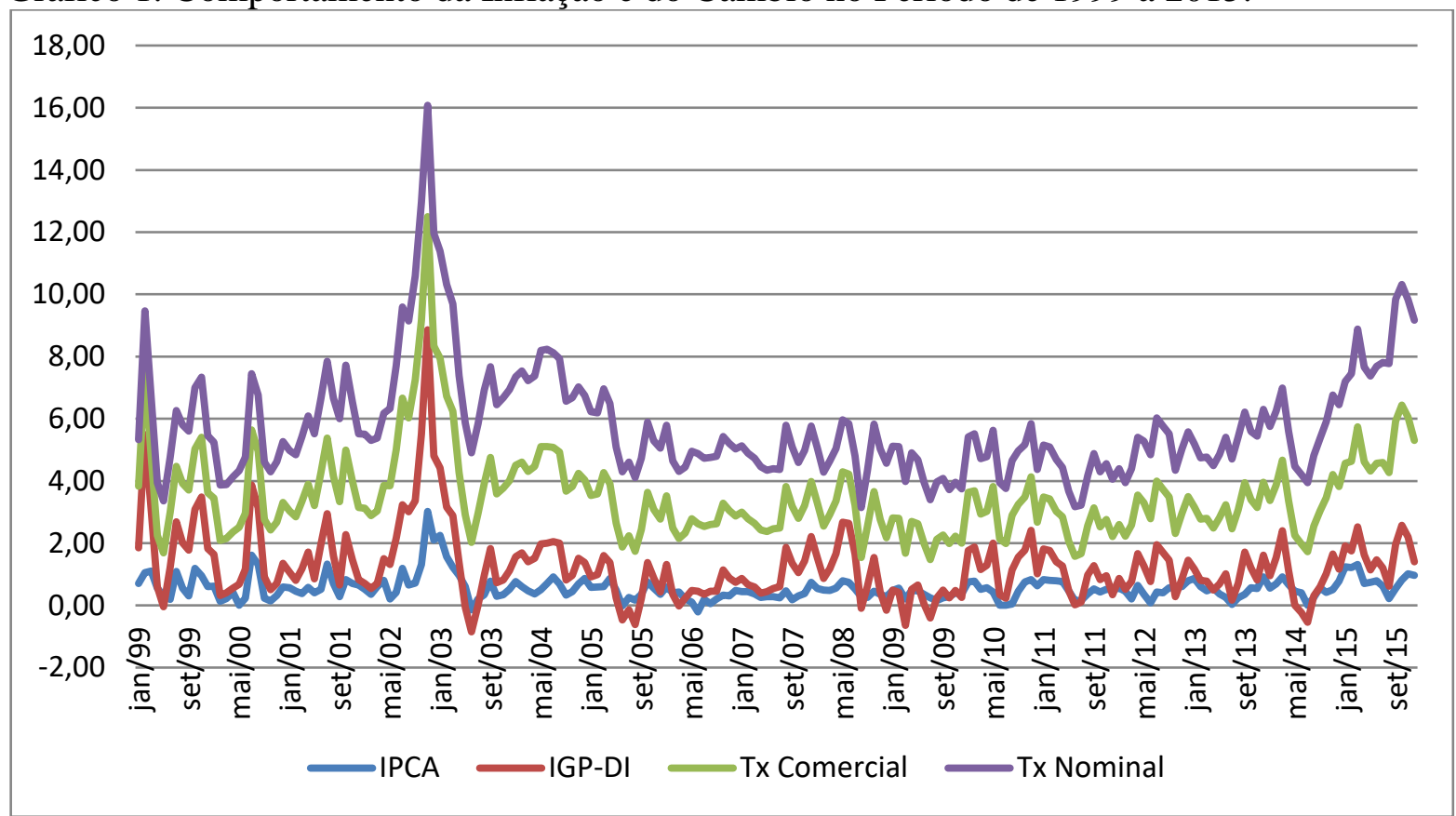

Nota: Fonte: Elaborado pelos autores com base nos dados do Ipea data (2016).

De forma específica, o Índice de Preços ao Consumidor Amplo (IPCA), índice oficial do governo (anexo 1), de acordo com Assaf (2012), é o mais relevante do ponto de vista de política econômica e o Conselho Monetário Nacional o selecionou como referência para o sistema de metas de inflação. Assaf afirma também que esse índice mede “(...) a variação de preços de um conjunto de produtos e serviços consumidos pelas famílias. Comparam os preços verificados nos 30 dias do período de referência com os 30 dias do período-base" (Assaf, 2012, p. 32).

Outro indicador utilizado (anexo 2) é o Índice Geral de Preços - Disponibilidade Interna (IGP-DI), que, para Furtado (2012), serviu como indicador oficial da inflação até 1985. Esse índice reflete a evolução dos preços captada pelo Índice de Preços por Atacado (IPA), Índice de Preços ao Consumidor (IPC-FGV) e Índice Nacional de Preços da Construção Civil (INCC). De acordo com Assaf (2012), atualmente esse índice, o IGPDI, é utilizado de maneira contratual para a correção de determinados preços administrados.

Para o câmbio será utilizada a taxa de câmbio real/dólar comercial, em preço de venda do fim do período (anexo 3). Segundo o Banco Central do Brasil, existe um único mercado de câmbio legal no país, que é conhecido como câmbio comercial, nele está incluso as operações realizadas no mercado de câmbio, como as exportações, importações e transferências financeiras. Por sua vez, a taxa de câmbio nominal (anexo 4) é a taxa que normalmente é divulgada pelas instituições financeiras e, Lopes e Vasconcellos (2014) afirmam que a taxa de câmbio nominal é a relação entre quantidades de moedas. Nesse trabalho será utilizada a taxa de câmbio nominal, real/dólar, comercial, preço de venda, média do período. 


\section{INFLUÊNCIA DA TAXA DE CÂMBIO SOBRE A INFLAÇÃO NA ECONOMIA BRASILEIRA (1999-2015)}

De acordo com os trabalhos de Goldfajn e Werlang (2000), Campa e Goldberg (2002) e Maciel (2006), os principais determinantes para que aconteça o pass-through são: o hiato do produto; o ambiente inflacionário; o grau de abertura da economia e o desalinhamento da taxa de câmbio real. Maciel (2006, p. 11) aponta que "(...) o hiato do produto é definido pelos desvios do produto em relação ao seu valor de longo prazo (...)", em um ambiente onde o hiato positivo do produto aumente o repasse cambial para a inflação é intensificado. O mesmo enfatiza que o ambiente inflacionário "(...) reflete a frequência na qual os agentes remarcam seus preços baseando-se na taxa de inflação passada (...)", quanto maior o ambiente inflacionário e persistência da inflação, mais fácil de repassar os aumentos da taxa de câmbio para os preços. Ainda de acordo com o autor, o grau de abertura da economia é definido através da soma das importações e das exportações como proporção do PIB. Quanto maior o grau de abertura da economia maior o repasse da taxa de câmbio para a inflação. De acordo com o autor, no que se refere ao desalinhamento da taxa de câmbio real, quanto mais sobrevalorizada a taxa de câmbio real estiver, maiores serão as expectativas de uma depreciação futura e, assim, maior será o efeito de uma variação cambial sobre a inflação.

Em relação ao ferramental utilizado por este trabalho, Bruni (2008) considera que a análise da correlação determina uma medida numérica do grau da relação entre duas, ou mais, variáveis. Essa análise é útil quando se tem por objetivo determinar as variáveis potencialmente importantes. Os dados analisados neste trabalho foram encontrados no site do Instituto de Pesquisa Econômica Aplicada (IPEA), como já apresentados anteriormente, e serão medidos por meio dos coeficientes de correlação de Pearson e Spearman.

O coeficiente de Pearson ( $r_{p}$ ) é descrito, segundo Lira e Chaves (2006), como um indicador que analisa a interdependência entre duas variáveis. Já para Moore (2010, p. 100-101) “(...) o coeficiente de correlação de Pearson (r) é uma medida de associação linear entre variáveis". De acordo com Figueiredo e Silva (2009), o coeficiente de Pearson varia de -1 a 1 , onde, o sinal indica a direção do relacionamento e o valor demonstra a força da relação entre as variáveis, portanto, ainda segundo os autores, uma correlação perfeita (-1 ou 1) “(...) indica que o escore de uma variável pode ser determinado exatamente ao se saber o escore da outra." Sendo assim, uma correlação de valor zero indicará o contrário, ou seja, que não existe relação linear entre as variáveis.

Para se classificar qualitativamente, será utilizada a escala de Callegari Jacques (2003, p. 90), onde: se $0,0<\left|r_{p}\right|<0,3$, observa-se fraca correlação linear; se $0,3 \leq\left|r_{p}\right|<$ 0,6 , observa-se moderada correlação linear; se $0,6 \leq\left|r_{p}\right|<0,9$, observa-se forte correlação linear; se $0,9 \leq\left|r_{p}\right|<1,0$, observa-se correlação linear muito forte. Com isso, quanto mais perto de 1, independente do sinal, maior é o grau de correlação entre as variáveis e quanto mais perto de zero, menor é a força da mesma.

O coeficiente de Spearman $\left(r_{s}\right)$, se baseia no ordenamento e é, segundo Siegel e Castellan (2006, p. 266), uma medida de associação entre duas variáveis onde é necessário que as mesmas sejam medidas, sobretudo, em uma escala ordinal, formandose duas séries em ordem. Sendo assim, se verifica a possibilidade de duas hipóteses: i) Hipótese $\mathrm{H}_{0}$, onde não há interligação entre as variáveis em questão e ii) Hipótese $\mathrm{H}_{1}$, em que se observa essa interligação. De acordo com Gujarati (2006, p. 104), “(...) um teste de significância é um procedimento em que os resultados amostrais são usados para verificar a veracidade ou a falsidade de uma hipótese nula". O intervalo de confiança do coeficiente de correlação, teste de hipótese, será feito a partir do teste t de Student, comparando $t$ calculado, demonstrado na equação, com o t crítico (com n-2 graus de liberdade e nível de significância de 1\%). 


\section{INFLUÊNCIA DA TAXA DE CÂMBIO SOBRE A INFLAÇÃO NA ECONOMIA BRASILEIRA (1999-2015)}

$$
t=r_{s} \sqrt{\frac{n-2}{1-r_{s}^{2}}} \sim t_{n-2}
$$

Onde:

$t$ é a estatística do teste (t calculado);

$r_{s}$ é o Coeficiente de Correlação de Spearman; e

$n$ representa a amostra.

Pontes (2010) sustenta que o coeficiente de correlação de Spearman “(...) nada mais é que o coeficiente de correlação linear de Pearson aplicado aos postos dos dados, obtidos independentemente para cada variável". Diferente do coeficiente de Pearson, onde para que ele seja igual a 1 ou -1 , a variável $Y$ deve ser função linear da variável $X$, os valores 1 ou - 1 para o coeficiente de correlação de Spearman são fáceis de acontecerem na prática. Na próxima seção serão apresentados os resultados das análises juntamente com os coeficientes de correlação de Pearson e Spearman, finalizando com as devidas conclusões.

\section{RESULTADOS E DISCUSSÕES}

Para dar início aos cálculos de correlação, primeiramente foi analisada a base de dados para verificação de como o câmbio influencia a inflação. De acordo com Figueiredo e Gouveia (2011), estudos demonstram que as variações na taxa de câmbio raramente se refletem imediatamente ou inteiramente para a inflação. Segundo Goldfajn e Werlang (2000), o pass-through cambial no Brasil chega ao seu valor máximo em 12 meses.

Tabela 1. Sistema de defasagem na base de dados de onze meses $\left(\mathrm{T}_{0}\right.$ a $\left.\mathrm{T}_{-11}\right)$.

\begin{tabular}{|c|c|c|c|c|c|c|c|c|c|c|c|}
\hline 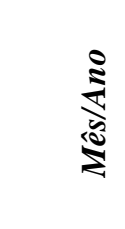 & 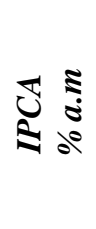 & 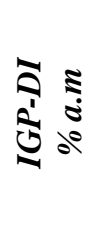 & 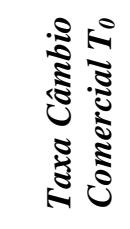 & 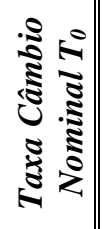 & 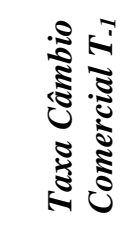 & 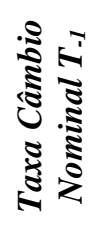 & 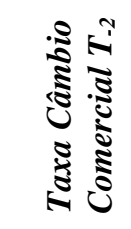 & 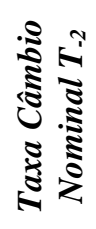 & $\ldots$ & 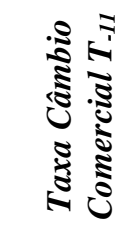 & 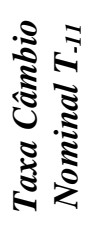 \\
\hline jan/99 & 0,70 & 1,15 & 1,9832 & 1,50 & - & - & - & - & $\cdots$ & - & - \\
\hline fev/99 & 1,05 & 4,44 & 2,0648 & 1,91 & 1,9832 & 1,50 & - & - & $\ldots$ & - & - \\
\hline mar/99 & 1,10 & 1,98 & 1,7220 & 1,90 & 2,0648 & 1,91 & 1,9832 & 1,50 & $\cdots$ & - & - \\
\hline abr/99 & 0,56 & 0,03 & 1,6607 & 1,69 & 1,7220 & 1,90 & 2,0648 & 1,91 & $\cdots$ & - & - \\
\hline$\vdots$ & $\vdots$ & $\vdots$ & $\vdots$ & $\vdots$ & $\vdots$ & $\vdots$ & $\vdots$ & $\vdots$ & $\vdots$ & $\vdots$ & $\vdots$ \\
\hline $\mathrm{dez} / 99$ & 0,60 & 1,23 & 1,7890 & 1,84 & 1,9227 & 1,93 & 1,9530 & 1,97 & $\cdots$ & 1,9832 & 1,50 \\
\hline $\mathrm{jan} / 00$ & 0,62 & 1,02 & 1,8024 & 1,80 & 1,7890 & 1,84 & 1,9227 & 1,93 & $\cdots$ & 2,0648 & 1,91 \\
\hline$\vdots$ & $\vdots$ & $\vdots$ & $\vdots$ & $\vdots$ & $\vdots$ & $\vdots$ & $\vdots$ & $\vdots$ & $\vdots$ & $\vdots$ & $\vdots$ \\
\hline nov/15 & 1,01 & 1,19 & 3,8506 & 3,78 & 3,8589 & 3,88 & 3,9729 & 3,91 & $\ldots$ & 2,6562 & 2,64 \\
\hline $\mathrm{dez} / 15$ & 0,96 & 0,44 & 3,9048 & 3,87 & 3,8506 & 3,78 & 3,8589 & 3,88 & $\ldots$ & 2,6623 & 2,63 \\
\hline
\end{tabular}

Nota: Fonte: Elaborado pelos autores. 


\section{INFLUÊNCIA DA TAXA DE CÂMBIO SOBRE A INFLAÇÃO NA ECONOMIA BRASILEIRA (1999-2015)}

Na Tabela 1 pode-se observar que foi necessária uma defasagem na base de dados, sendo que no período $\mathrm{T}_{0}$ não há defasagem, ou seja, taxa de câmbio e índice inflacionário do mesmo mês sendo relacionados, e no período $\mathrm{T}_{-11}$ há uma defasagem de onze meses, taxa de câmbio relacionada com um índice inflacionário após onze meses. Essa defasagem se fez necessária para verificar a significância da correlação da inflação em relação à taxa de câmbio, e assim, verificar quanto tempo, após a taxa de câmbio ser aplicada, ela irá afetar a inflação. Assim, os valores obtidos na base de dados utilizados para a inflação vão do período de dezembro de 1999 a dezembro de 2015.

Em seguida, realizaram-se os cálculos de acordo com os coeficientes de correlação de Pearson e Spearman, apresentados na seção anterior, encontrando então, duas tabelas de correlação, onde é possível verificar quais os períodos em que a taxa de câmbio possui maior influência sobre a inflação. Na Tabela 2 encontram-se os resultados, após os cálculos do coeficiente de correlação de Pearson, e na Tabela 3, resultados após os cálculos do coeficiente de correlação de Spearman. Nos dois casos pode-se observar que alguns valores não se mostraram estatisticamente significantes, a correlação será significativa ao nível de 0,01 e 0,05 para um teste bicaudal (valores destacados em cinza nas tabelas).

Tabela 2. Coeficiente de Correlação de Pearson.

\begin{tabular}{|c|c|c|c|c|}
\hline & \multicolumn{2}{|c|}{ IPCA } & \multicolumn{2}{|c|}{$I G P-D I$} \\
\hline & $\begin{array}{c}\text { Pearson } \\
\text { Correlation }\end{array}$ & $\begin{array}{l}\text { Sig. }(2- \\
\text { tailed })\end{array}$ & $\begin{array}{c}\text { Pearson } \\
\text { Correlation }\end{array}$ & $\begin{array}{l}\text { Sig. }(2- \\
\text { tailed })\end{array}$ \\
\hline Taxa Câmbio Comercial To & $0,431 * *$ & 0,000 & $0,352 * *$ & 0,000 \\
\hline Taxa Câmbio Nominal $T_{0}$ & $0,438 * *$ & 0,000 & $0,348 * *$ & 0,000 \\
\hline Taxa Câmbio Comercial $T_{-1}$ & $0,443 * *$ & 0,000 & $0,342 * *$ & 0,000 \\
\hline Taxa Câmbio Nominal $T_{-1}$ & $0,458 * *$ & 0,000 & $0,314 * *$ & 0,000 \\
\hline Taxa Câmbio Comercial $T_{-2}$ & $0,457 * *$ & 0,000 & $0,289 * *$ & 0,000 \\
\hline Taxa Câmbio Nominal $T_{-2}$ & $0,425 * *$ & 0,000 & $0,232 * *$ & 0,001 \\
\hline Taxa Câmbio Comercial $T_{-3}$ & $0,397 * *$ & 0,000 & $0,205 * *$ & 0,004 \\
\hline Taxa Câmbio Nominal $T_{-3}$ & $0,373 * *$ & 0,000 & $0,165^{*}$ & 0,022 \\
\hline Taxa Câmbio Comercial $T_{-4}$ & $0,365 * *$ & 0,000 & $0,159 *$ & 0,027 \\
\hline Taxa Câmbio Nominal $T_{-4}$ & $0,308 * *$ & 0,000 & 0,11 & 0,145 \\
\hline Taxa Câmbio Comercial $T_{-5}$ & $0,284 * *$ & 0,000 & 0,09 & 0,226 \\
\hline Taxa Câmbio Nominal T-5 & $0,244 * *$ & 0,001 & 0,06 & 0,416 \\
\hline Taxa Câmbio Comercial $T_{-6}$ & $0,226 * *$ & 0,002 & 0,06 & 0,442 \\
\hline Taxa Câmbio Nominal $T_{-6}$ & $0,186 * *$ & 0,009 & 0,03 & 0,689 \\
\hline Taxa Câmbio Comercial $T_{-7}$ & $0,165^{*}$ & 0,022 & 0,02 & 0,738 \\
\hline Taxa Câmbio Nominal $T_{-7}$ & 0,13 & 0,062 & 0,01 & 0,900 \\
\hline Taxa Câmbio Comercial $T_{-8}$ & 0,11 & 0,113 & 0,01 & 0,878 \\
\hline Taxa Câmbio Nominal $T_{-8}$ & 0,09 & 0,192 & 0,01 & 0,886 \\
\hline Taxa Câmbio Comercial T.9 & 0,09 & 0,238 & 0,02 & 0,828 \\
\hline Taxa Câmbio Nominal T.9 & 0,09 & 0,208 & 0,03 & 0,711 \\
\hline Taxa Câmbio Comercial $T_{-10}$ & 0,09 & 0,235 & 0,03 & 0,665 \\
\hline Taxa Câmbio Nominal T-10 & 0,08 & 0,255 & 0,04 & 0,565 \\
\hline
\end{tabular}



BRASILEIRA (1999-2015)

\begin{tabular}{l||ll||cc} 
Taxa Câmbio Comercial T-11 & 0,07 & 0,317 & 0,04 & 0,567 \\
Taxa Câmbio Nominal T-11 & 0,08 & 0,264 & 0,05 & 0,484 \\
\hline
\end{tabular}

Nota: Fonte: Elaborado pelos autores.

**. Correlation issignificant at the 0.01 level (2-tailed).

*. Correlation issignificant at the 0.05 level (2-tailed).

Para demonstrar os resultados da correlação de Pearson, apresenta-se a Tabela 2, com as informações para interpretação dos dados. Pode-se destacar, ao analisar os dados, que quando se trata do IPCA foram encontrados valores com confiança de $100 \%$ a $98 \%$ até o sétimo mês, sendo que, até o quarto mês a correlação é moderada $\left(0,3 \leq\left|r_{p}\right|<0,6\right)$ e segue até o sétimo com uma correlação fraca $\left(0,0<\left|r_{p}\right|<0,3\right)$ (valores significativos). Quando se trata do IGP-DI, têm-se valores com confiança de $100 \%$ a $97 \%$ até o quarto mês, sendo que somente no primeiro mês a correlação foi moderada, e segue com uma correlação fraca até o quarto mês.

Visto de outra forma, os dados indicam (ainda de acordo com a Tabela 2) que as taxas de câmbio (comercial e nominal) influenciam o IPCA até o sétimo mês, em outras palavras, a título de exemplo, a taxa de câmbio de janeiro tem correlação com o IPCA de julho (do mesmo ano), por sua vez para o IGP-DI essa influência vai até o quarto mês.

Ao se analisar os dados da correlação de Pearson, ainda na Tabela 2, em um primeiro momento, percebe-se que no caso do IGP-DI, a correlação do câmbio é menor do que a observada sobre o IPCA, o que difere da análise apresentada por Paula (2005). Para o autor o IGP-DI teria uma maior sensibilidade a taxa de câmbio, pois, $60 \%$ da sua composição é constituída por preço de atacado, já o IPCA sofre influência da taxa de câmbio direta e indiretamente, no primeiro caso pela apreciação, ou depreciação cambial, sobre os custos de produção das empresas e, no segundo, via IGP, que é o índice utilizado para reajustar alguns preços administrados. O repasse de uma variação cambial para os preços ocorrerá, como já mencionado, em maior ou menor grau, dependendo da abertura da economia. O processo de abertura da economia brasileira fez com que o alcance do impacto direto das variações cambiais aumentasse, já que a participação das importações e exportações no PIB também aumentou.

Tabela 3. Coeficiente de Correlação de Spearman.

\begin{tabular}{|c|c|c|c|c|c|c|}
\hline & \multicolumn{3}{|c|}{ IPCA } & \multicolumn{3}{|c|}{$I G P-D I$} \\
\hline & $\begin{array}{l}\text { Correlation } \\
\text { Coefficient }\end{array}$ & $\begin{array}{c}\text { Sig. }(2- \\
\text { tailed) }\end{array}$ & $T$ & $\begin{array}{c}\text { Correlation } \\
\text { Coefficient }\end{array}$ & $\begin{array}{c}\text { Sig. }(2- \\
\text { tailed) }\end{array}$ & $T$ \\
\hline Taxa Câmbio Comercial $T_{0}$ & 0,281 & 0,0000 & 4,046 & 0,161 & 0,025 & 2,254 \\
\hline Taxa Câmbio Nominal $T_{0}$ & 0,285 & 0,0000 & 4,109 & 0,168 & 0,019 & 2,355 \\
\hline Taxa Câmbio Comercial $T_{-1}$ & 0,283 & 0,0000 & 4,078 & 0,145 & 0,045 & 2,025 \\
\hline Taxa Câmbio Nominal $T_{-1}$ & 0,293 & 0,0000 & 4,235 & 0,128 & 0,076 & 1,782 \\
\hline Taxa Câmbio Comercial $T_{-2}$ & 0,297 & 0,0000 & 4,298 & 0,099 & 0,169 & 1,382 \\
\hline Taxa Câmbio Nominal T $T_{-2}$ & 0,282 & 0,0000 & 4,062 & 0,081 & 0,262 & 1,125 \\
\hline Taxa Câmbio Comercial $T_{-3}$ & 0,272 & 0,0001 & 3,906 & 0,068 & 0,344 & 0,949 \\
\hline Taxa Câmbio Nominal $T_{-3}$ & 0,253 & 0,0003 & 3,614 & 0,053 & 0,460 & 0,739 \\
\hline Taxa Câmbio Comercial T-4 & 0,237 & 0,0008 & 3,371 & 0,038 & 0,597 & 0,529 \\
\hline Taxa Câmbio Nominal T-4 & 0,226 & 0,0016 & 3,206 & 0,027 & 0,710 & 0,371 \\
\hline Taxa Câmbio Comercial T-5 & 0,206 & 0,004 & 2,909 & 0,014 & 0,841 & 0,200 \\
\hline Taxa Câmbio Nominal $T_{-5}$ & 0,191 & 0,0078 & 2,689 & 0,013 & 0,855 & 0,183 \\
\hline Taxa Câmbio Comercial T-6 & 0,169 & 0,0186 & 2,369 & 0,022 & 0,762 & 0,303 \\
\hline Taxa Câmbio Nominal T-6 & 0,169 & 0,0184 & 2,369 & 0,019 & 0,788 & 0,269 \\
\hline Taxa Câmbio Comercial T-7 & 0,159 & 0,0275 & 2,226 & 0,032 & 0,662 & 0,437 \\
\hline Taxa Câmbio Nominal $T_{-7}$ & 0,155 & 0,0314 & 2,168 & 0,031 & 0,669 & 0,428 \\
\hline Taxa Câmbio Comercial $T_{-8}$ & 0,141 & 0,0509 & 1,964 & 0,043 & 0,556 & 0,589 \\
\hline Taxa Câmbio Nominal $T_{-8}$ & 0,139 & 0,0539 & 1,939 & 0,049 & 0,498 & 0,679 \\
\hline Taxa Câmbio Comercial T.9 & 0,127 & 0,0780 & 1,772 & 0,055 & 0,446 & 0,764 \\
\hline
\end{tabular}




\section{INFLUÊNCIA DA TAXA DE CÂMBIO SOBRE A INFLAÇÃO NA ECONOMIA BRASILEIRA (1999-2015)}

\begin{tabular}{l||ccc||ccc} 
Taxa Câmbio Nominal T-9 & 0,136 & 0,0602 & 1,890 & 0,067 & 0,354 & 0,928 \\
Taxa Câmbio Comercial T-10 & 0,129 & 0,072 & 1,809 & 0,079 & 0,276 & 1,091 \\
Taxa Câmbio Nominal T-10 & 0,127 & 0,0786 & 1,768 & 0,079 & 0,275 & 1,095 \\
Taxa Câmbio Comercial T-11 & 0,125 & 0,0827 & 1,744 & 0,085 & 0,240 & 1,178 \\
Taxa Câmbio Nominal T-11 & 0,109 & 0,1286 & 1,526 & 0,077 & 0,289 & 1,063 \\
\hline
\end{tabular}

Nota: Fonte: Elaborado pelos autores.

**. Correlation is significant at the 0.01 level (2-tailed).

*. Correlation is significant at the 0.05 level (2-tailed).

No teste de hipótese do valor de Spearman para os dados que se referem ao IPCA, até o oitavo mês a hipótese nula $\left(\mathrm{H}_{0}\right)$, onde não há interligação entre as variáveis em questão, foi rejeitada. Com nível de significância de $1 \%$ obteve-se valores para o t calculado maiores que o $t$ crítico $\left(t_{c}=2,5763\right)$ variando entre 4,046 e 2,689 e com nível de significância de $5 \%\left(t_{c}=1,9602\right)$ os valores variaram entre 1,964 e 1,939 . Já para os dados que se referem ao IGP-DI, a hipótese nula $\left(\mathrm{H}_{0}\right)$ foi rejeitada somente no primeiro mês, com nível de significância de 5\% para o t calculado entre 2,254 e 2,025 $\left(t_{c}=1,9602\right)$. Nos demais meses, tanto para o IPCA quanto para o IGP-DI, o nível de confiança não é significativo.

Como mencionado anteriormente, após a Segunda Guerra, o controle da inflação tornou-se uma das metas prioritárias do governo e a política de estabilização mais bemsucedida foi o Plano Real, plano esse baseado em uma âncora cambial em um primeiro momento. Percebe-se então, durante a história econômica brasileira, vários momentos em que a taxa de câmbio foi utilizada no combate à inflação. $\mathrm{O}$ acompanhamento das variações no câmbio e da análise do impacto dessas alterações nos preços da economia foi uma das preocupações das autoridades monetárias. Nesse sentido, os resultados apresentados indicam que a taxa de câmbio possui ligação/correlação com o processo inflacionário. Essa relação depende da variação cambial nos preços de insumos e bens finais importados. Assim como, uma variação no volume de exportações que influenciam a oferta interna e consequentemente os preços.

\section{CONCLUSÕES}

Esta pesquisa focou-se a realizar uma revisão de literatura relativa à inflação e câmbio, e uma análise de dados para verificar a correlação entre os objetos de estudo. Ao longo da pesquisa, observou-se que em 1999, com a adoção do câmbio flutuante, a taxa de câmbio passou a influenciar a inflação de forma mais direta. Percebe-se então, que a taxa de câmbio tem uma forte influência na inflação. No caso brasileiro, o mecanismo de transmissão da política monetária para a inflação é mediado pela taxa de câmbio.

Por meio da análise dos coeficientes de correlação de Pearson e Spearman, percebe-se que a taxa de câmbio possui um efeito na inflação até o oitavo mês, após esse período, a correlação não é significativa. Apesar da literatura destacar que o IGP-DI teria uma influência do câmbio mais marcante, observa-se que a taxa de câmbio tem um efeito mais prolongado no IPCA já que para os dados correlacionados do IGP-DI mostra um efeito somente nos primeiros meses, até no máximo, o quarto mês, já para o IPCA o efeito se estende até o sétimo mês. Destaca-se que estes resultados se alinham aos observados em Couto e Fraga (2014), que analisou a importância do IGP-DI. Voltando a falar dos prazos, neste particular vale lembrar que, segundo Goldfajn e Werlang (2000), o passthrough cambial no Brasil chegaria ao seu valor máximo em 12 meses, contudo de acordo com os dados a relação não se mostrou significativa até o $12^{\circ}$. mês.

De toda sorte, existem vários modelos na literatura econômica, como os citados neste trabalho, que mensuram o quanto um aumento ou uma redução da taxa de câmbio 


\section{INFLUÊNCIA DA TAXA DE CÂMBIO SOBRE A INFLAÇÃO NA ECONOMIA BRASILEIRA (1999-2015)}

faz com que a inflação aumente, ou tenha uma queda. O que se observa é que a variação na taxa de câmbio passou a ser o principal mecanismo do Sistema Monetário Internacional para o controle da inflação. De acordo com os dados obtidos, percebe-se que a elevação, ou diminuição da inflação, pode resultar da depreciação ou apreciação da taxa de câmbio, mostrando assim, que esta é uma variável chave para que o movimento da inflação seja entendido.

Por fim, espera-se que esta pesquisa ofereça subsídios para trabalhos futuros, que possam ser realizados no sentido de avançar no debate sobre os efeitos da política cambial sobre os índices inflacionários, assim como, calcular o grau de pass-through cambial, tanto para a economia brasileira, quanto para de outros países.

\section{REFERÊNCIAS}

Almeida, M., Fontes, R., Arbex, M. A.(2000). Retrospectiva dos regimes cambiais brasileiros com ênfase em bandas de câmbio. Ensaios Fee, Porto Alegre, 21(1) 7-43. http://revistas.fee.tche.br/index.php/ensaios/article/viewFile/1959/2338

Assaf, A. Neto (2012). Mercado financeiro. São Paulo: Atlas

Baer, W. (2004). A economia brasileira. São Paulo: Editora Nobel.

Banco Central do Brasil. (2016). Glossário. Recuperado de http://www.bcb.gov.br/glossario.asp?Definicao=641\&idioma=P\&idpai=GLOSSARIO

Belaisch, A. (2003). Exchange rate pass-through in Brazil. IMF Working Paper, n. 141, Julho, 2003.

Betts, C. \& Devereux, M. B. (1996). The Exchange rate in a model of pricing-to-market. European Eonomic Review. 1007-1021.

Bresser-Pereira, L. C. (2007). Macroeconomia da estagnação: crítica da ortodoxia convencional no Brasil pós-1994. São Paulo: Editora 34.

Bruni, A. L. (2008). Estatística aplicada à gestão empresarial. São Paulo: Atlas.

Burstein, A., Eichenbaum, M., Rebelo, S. (2005). Modeling exchange rate pass through after larged evaluations. http://www.econ.ucla.edu/arielb/DevaluationsModel.pdf.

Callegari Jacques, S. M. (2003). Bioestatística: princípios e aplicações. Porto Alegre: Artmed.

Campa, J. M. \& Goldberg, L. S. (2002). Exchange rate pass-through into import prices: a macro or micro phenomenon?Federal Reserve Bank of New York. https://www.newyorkfed.org/medialibrary/media/research/staff_reports/sr149.pdf.

Couto, S. V. V. \& Fraga, G. J. (2014). O pass-through da taxa de câmbio para índices de preços: análise empírica para o Brasil. Rev. Econ. Contemp., Rio de Janeiro. 18(3) 333356, http://www.synergiaeditora.com.br/upl/arqs/book-rec-183pdf1.pdf\#page=5.

Cunningham, A. \& Haldane, A. W. (2000). The monetary transmission mechanism in the United kingdom: pass-throug hand policy rules. Central Bank of Chile Working Paper, Santiago.

Figueiredo, D. B. Filho \& Silva, J. A. Jr. (2009). Desvendando os mistérios do coeficiente de correlação de Pearson (r). Revista Política Hoje. 18(1) 115-146.

Figueiredo, F. M. R. \& Gouvea, S. (2011). Repasse cambial para a inflação: o papel da rigidez de preços. In: Banco Central do Brasil. Dez anos de metas para a inflação - 19992009. Brasília: Banco Central do Brasil. 127-168.

Fraga, A. Neto. (2011). Dez anos de metas para a inflação. In: Banco Central do Brasil. Dez Anos de Metas para a Inflação - 1999-2009. Banco Central do Brasil. 27-34.

Furtado, M. B. (2012). Síntese da economia brasileira. Rio de Janeiro: LTC. 


\section{INFLUÊNCIA DA TAXA DE CÂMBIO SOBRE A INFLAÇÃO NA ECONOMIA BRASILEIRA (1999-2015)}

Gagnon, E. (2007). Price setting duringlowand high inflation: evidence from Mexico. Board of Governors of the Federal Reserve System International Finance Discussion Papers. http://www.federalreserve.gov/pubs/ifdp/2007/896/ifdp896.pdf.

Garofalo, E. Filho. (2005). Câmbio\$: princípios básicos do mercado cambial. São Paulo: Saraiva.

Goldfajn, I. \& Werlang, S. R. C. (2000). The pass-through from depreciation to inflation: a panel study. Banco Central do Brasil: Working Paper series, Brasília.

Gujarati, D. N. (2006). Econometria Básica. Rio de Janeiro: Elsevier.

Instituto de Pesquisa Econômica Aplicada - Ipea data. (2016). Dados macroeconômicos. http://www.ipeadata.gov.br

Lanzana, A. E. T. (2010). Economia Brasileira: fundamentos e atualidade. São Paulo: Atlas.

Lira, S. \& Chaves, A. Neto. (2006). Coeficientes de correlação para variáveis ordinais e dicotômicas derivados do coeficiente linear de Pearson. Uberlândia www.seer.ufu.br/index.php/cieng/article/download/529/489

Lopes, J. C. \& Rossetti, J. P. (2011). Economia Monetária. São Paulo: Atlas.

Lopes, L. M. \& Vasconcellos, M. A. S. (organizadores). (2014). Manual de macroeconomia: nível básico e nível intermediário. São Paulo: Atlas.

Maciel, L. F. P. (2006). Pass-through cambial: uma estimação do caso brasileiro. Dissertação (Mestrado em Economia) - Escola de Pós-graduação em Economia, Fundação Getúlio Vargas, Rio de Janeiro. http://bibliotecadigital.fgv.br/dspace/bitstream/handle/10438/1612/043202010_Disserta cao_Luiz_Felipe_Maciel.pdf?sequence $=1$

Menezes, G. \& Fernandez, R. N. (2012). Análise do efeito pass-through cambial para a formação dos índices de preços no Brasil (1999 - 2011). Encontro de Economia, Pontifícia Universidade Católica do Rio Grande do Sul. http://www.pucrs.br/eventos/encontroeconomia/download/mesas/EfeitoPassthrough.pdf

Moore, D. S. (2010). The basic practice of statistics. New York: Macmillan.

Paula, L. F. (2005). Uma avaliação do regime de metas de inflação no Brasil. Valor Econômico. São Paulo.

Pollard, P. S. \& Coughlin, C. C. (2005). Pass-through estimates and the choice of Exchange rate index. The Federal Reserve Bank of St. Louis. https://core.ac.uk/download/pdf/6608227.pdf

Pontes, A. C. F. (2010). Ensino da correlação de postos no ensino médio. In: Simpósio Nacional de Probabilidade e Estatística (SINAPE). São Pedro (SP). Anais... IME/Unicamp.

http://www.ime.unicamp.br/sinape/sites/default/files/EnsinoCorrelacaoDePostos.pdf Rego, J. M. \& Marques, R. M. (Orgs) et al. (2013). Economia Brasileira. São Paulo: Saraiva.

Siegel, S. \& Castellan, N. J. (2006). Estatística não-paramétrica para as ciências do comportamento. Porto Alegre: Bookman.

Vasconcellos, M. A. S. \& Garcia, M. E. (2011). Fundamentos de Economia. São Paulo: Saraiva.

Werneck, R. L. F. (2014). Consolidação da estabilização e reconstrução institucional, 1995-2002. In: Abreu, M. P. (Org.). A ordem do Progresso: Dois séculos de política econômica no Brasil. Rio de Janeiro: Elsevier, 331-356. 
INFLUÊNCIA DA TAXA DE CÂMBIO SOBRE A INFLAÇÃO NA ECONOMIA BRASILEIRA (1999-2015) 


\section{INFLUÊNCIA DA TAXA DE CÂMBIO SOBRE A INFLAÇÃO NA ECONOMIA BRASILEIRA (1999-2015)}

ANEXOS

Anexo 1. Índice de Preços ao Consumidor Amplo (\% a.m) no período de 1999 a 2015.

\begin{tabular}{|c|c|c|c|c|c|c|c|}
\hline Mês/Ano & $\begin{array}{c}\text { IPCA (\% } \\
\text { a.m) }\end{array}$ & Mês/Ano & $\begin{array}{c}\text { IPCA (\% } \\
\text { a.m) }\end{array}$ & Mês/Ano & $\begin{array}{l}\text { IPCA (\% } \\
\text { a.m) }\end{array}$ & Mês/Ano & $\begin{array}{c}\text { IPCA (\% } \\
\text { a.m) }\end{array}$ \\
\hline 01/1999 & 0,70 & $04 / 2003$ & 0,97 & $07 / 2007$ & 0,24 & $10 / 2011$ & 0,43 \\
\hline 02/1999 & 1,05 & $05 / 2003$ & 0,61 & $08 / 2007$ & 0,47 & $11 / 2011$ & 0,52 \\
\hline 03/1999 & 1,10 & $06 / 2003$ & $-0,15$ & $09 / 2007$ & 0,18 & $12 / 2011$ & 0,50 \\
\hline 04/1999 & 0,56 & $07 / 2003$ & 0,20 & $10 / 2007$ & 0,30 & $01 / 2012$ & 0,56 \\
\hline 05/1999 & 0,30 & $08 / 2003$ & 0,34 & $11 / 2007$ & 0,38 & $02 / 2012$ & 0,45 \\
\hline 06/1999 & 0,19 & $09 / 2003$ & 0,78 & $12 / 2007$ & 0,74 & $03 / 2012$ & 0,21 \\
\hline 07/1999 & 1,09 & $10 / 2003$ & 0,29 & $01 / 2008$ & 0,54 & $04 / 2012$ & 0,64 \\
\hline 08/1999 & 0,56 & $11 / 2003$ & 0,34 & $02 / 2008$ & 0,49 & $05 / 2012$ & 0,36 \\
\hline 09/1999 & 0,31 & $12 / 2003$ & 0,52 & $03 / 2008$ & 0,48 & $06 / 2012$ & 0,08 \\
\hline $10 / 1999$ & 1,19 & $01 / 2004$ & 0,76 & $04 / 2008$ & 0,55 & 07/2012 & 0,43 \\
\hline $11 / 1999$ & 0,95 & $02 / 2004$ & 0,61 & $05 / 2008$ & 0,79 & $08 / 2012$ & 0,41 \\
\hline $12 / 1999$ & 0,60 & $03 / 2004$ & 0,47 & $06 / 2008$ & 0,74 & 09/2012 & 0,57 \\
\hline $01 / 2000$ & 0,62 & $04 / 2004$ & 0,37 & $07 / 2008$ & 0,53 & $10 / 2012$ & 0,59 \\
\hline $02 / 2000$ & 0,13 & $05 / 2004$ & 0,51 & $08 / 2008$ & 0,28 & $11 / 2012$ & 0,60 \\
\hline $03 / 2000$ & 0,22 & $06 / 2004$ & 0,71 & $09 / 2008$ & 0,26 & $12 / 2012$ & 0,79 \\
\hline $04 / 2000$ & 0,42 & $07 / 2004$ & 0,91 & $10 / 2008$ & 0,45 & $01 / 2013$ & 0,86 \\
\hline $05 / 2000$ & 0,01 & $08 / 2004$ & 0,69 & $11 / 2008$ & 0,36 & $02 / 2013$ & 0,60 \\
\hline $06 / 2000$ & 0,23 & 09/2004 & 0,33 & $12 / 2008$ & 0,28 & $03 / 2013$ & 0,47 \\
\hline $07 / 2000$ & 1,61 & $10 / 2004$ & 0,44 & $01 / 2009$ & 0,48 & $04 / 2013$ & 0,55 \\
\hline $08 / 2000$ & 1,31 & $11 / 2004$ & 0,69 & 02/2009 & 0,55 & $05 / 2013$ & 0,37 \\
\hline $09 / 2000$ & 0,23 & $12 / 2004$ & 0,86 & $03 / 2009$ & 0,20 & $06 / 2013$ & 0,26 \\
\hline $10 / 2000$ & 0,14 & $01 / 2005$ & 0,58 & $04 / 2009$ & 0,48 & $07 / 2013$ & 0,03 \\
\hline $11 / 2000$ & 0,32 & $02 / 2005$ & 0,59 & $05 / 2009$ & 0,47 & $08 / 2013$ & 0,24 \\
\hline $12 / 2000$ & 0,59 & $03 / 2005$ & 0,61 & $06 / 2009$ & 0,36 & $09 / 2013$ & 0,35 \\
\hline $01 / 2001$ & 0,57 & $04 / 2005$ & 0,87 & $07 / 2009$ & 0,24 & $10 / 2013$ & 0,57 \\
\hline $02 / 2001$ & 0,46 & $05 / 2005$ & 0,49 & 08/2009 & 0,15 & $11 / 2013$ & 0,54 \\
\hline $03 / 2001$ & 0,38 & $06 / 2005$ & $-0,02$ & $09 / 2009$ & 0,24 & $12 / 2013$ & 0,92 \\
\hline $04 / 2001$ & 0,58 & $07 / 2005$ & 0,25 & $10 / 2009$ & 0,28 & $01 / 2014$ & 0,55 \\
\hline $05 / 2001$ & 0,41 & $08 / 2005$ & 0,17 & $11 / 2009$ & 0,41 & $02 / 2014$ & 0,69 \\
\hline 06/2001 & 0,52 & $09 / 2005$ & 0,35 & $12 / 2009$ & 0,37 & $03 / 2014$ & 0,92 \\
\hline $07 / 2001$ & 1,33 & $10 / 2005$ & 0,75 & $01 / 2010$ & 0,75 & $04 / 2014$ & 0,67 \\
\hline $08 / 2001$ & 0,70 & $11 / 2005$ & 0,55 & $02 / 2010$ & 0,78 & $05 / 2014$ & 0,46 \\
\hline $09 / 2001$ & 0,28 & $12 / 2005$ & 0,36 & $03 / 2010$ & 0,52 & $06 / 2014$ & 0,40 \\
\hline $10 / 2001$ & 0,83 & $01 / 2006$ & 0,59 & $04 / 2010$ & 0,57 & $07 / 2014$ & 0,01 \\
\hline $11 / 2001$ & 0,71 & $02 / 2006$ & 0,41 & $05 / 2010$ & 0,43 & $08 / 2014$ & 0,25 \\
\hline $12 / 2001$ & 0,65 & $03 / 2006$ & 0,43 & $06 / 2010$ & 0,00 & $09 / 2014$ & 0,57 \\
\hline $01 / 2002$ & 0,52 & $04 / 2006$ & 0,21 & $07 / 2010$ & 0,01 & $10 / 2014$ & 0,42 \\
\hline $02 / 2002$ & 0,36 & $05 / 2006$ & 0,10 & $08 / 2010$ & 0,04 & $11 / 2014$ & 0,51 \\
\hline $03 / 2002$ & 0,60 & 06/2006 & $-0,21$ & 09/2010 & 0,45 & $12 / 2014$ & 0,78 \\
\hline $04 / 2002$ & 0,80 & $07 / 2006$ & 0,19 & $10 / 2010$ & 0,75 & $01 / 2015$ & 1,24 \\
\hline $05 / 2002$ & 0,21 & $08 / 2006$ & 0,05 & $11 / 2010$ & 0,83 & $02 / 2015$ & 1,22 \\
\hline $06 / 2002$ & 0,42 & $09 / 2006$ & 0,21 & $12 / 2010$ & 0,63 & $03 / 2015$ & 1,32 \\
\hline $07 / 2002$ & 1,19 & $10 / 2006$ & 0,33 & $01 / 2011$ & 0,83 & $04 / 2015$ & 0,71 \\
\hline $08 / 2002$ & 0,65 & $11 / 2006$ & 0,31 & $02 / 2011$ & 0,80 & $05 / 2015$ & 0,74 \\
\hline $09 / 2002$ & 0,72 & $12 / 2006$ & 0,48 & $03 / 2011$ & 0,79 & $06 / 2015$ & 0,79 \\
\hline $10 / 2002$ & 1,31 & $01 / 2007$ & 0,44 & $04 / 2011$ & 0,77 & $07 / 2015$ & 0,62 \\
\hline $11 / 2002$ & 3,02 & $02 / 2007$ & 0,44 & $05 / 2011$ & 0,47 & $08 / 2015$ & 0,22 \\
\hline $12 / 2002$ & 2,10 & $03 / 2007$ & 0,37 & $06 / 2011$ & 0,15 & $09 / 2015$ & 0,54 \\
\hline $01 / 2003$ & 2,25 & $04 / 2007$ & 0,25 & $07 / 2011$ & 0,16 & $10 / 2015$ & 0,82 \\
\hline $02 / 2003$ & 1,57 & $05 / 2007$ & 0,28 & 08/2011 & 0,37 & $11 / 2015$ & 1,01 \\
\hline $03 / 2003$ & 1,23 & $06 / 2007$ & 0,28 & $09 / 2011$ & 0,53 & $12 / 2015$ & 0,96 \\
\hline
\end{tabular}

Nota: Fonte: Ipea data (2016).

Anexo 2. Índice Geral de Preços - Disponibilidade Interna (\% a.m), no período de 1999 a 2015 . 
INFLUÊNCIA DA TAXA DE CÂMBIO SOBRE A INFLAÇÃO NA ECONOMIA BRASILEIRA (1999-2015)

\begin{tabular}{|c|c|c|c|c|c|c|c|}
\hline Mês/Ano & $\begin{array}{l}\text { IGP-DI } \\
(\% \text { a.m })\end{array}$ & Mês/Ano & $\begin{array}{l}\text { IGP-DI } \\
(\% \text { a.m })\end{array}$ & Mês/Ano & $\begin{array}{l}\text { IGP-DI } \\
(\% \text { a.m })\end{array}$ & Mês/Ano & $\begin{array}{l}\text { IGP-DI } \\
\text { (\% a.m) }\end{array}$ \\
\hline $01 / 1999$ & 1,15 & $04 / 2003$ & 0,41 & $07 / 2007$ & 0,37 & $10 / 2011$ & 0,40 \\
\hline $02 / 1999$ & 4,44 & $05 / 2003$ & $-0,67$ & $08 / 2007$ & 1,39 & $11 / 2011$ & 0,43 \\
\hline 03/1999 & 1,98 & $06 / 2003$ & $-0,70$ & $09 / 2007$ & 1,17 & $12 / 2011$ & $-0,16$ \\
\hline 04/1999 & 0,03 & $07 / 2003$ & $-0,20$ & $10 / 2007$ & 0,75 & $01 / 2012$ & 0,30 \\
\hline 05/1999 & $-0,34$ & $08 / 2003$ & 0,62 & $11 / 2007$ & 1,05 & $02 / 2012$ & 0,07 \\
\hline $06 / 1999$ & 1,02 & $09 / 2003$ & 1,05 & $12 / 2007$ & 1,47 & $03 / 2012$ & 0,56 \\
\hline $07 / 1999$ & 1,59 & $10 / 2003$ & 0,44 & $01 / 2008$ & 0,99 & $04 / 2012$ & 1,02 \\
\hline 08/1999 & 1,45 & $11 / 2003$ & 0,48 & $02 / 2008$ & 0,38 & $05 / 2012$ & 0,91 \\
\hline 09/1999 & 1,47 & $12 / 2003$ & 0,60 & $03 / 2008$ & 0,70 & $06 / 2012$ & 0,69 \\
\hline $10 / 1999$ & 1,89 & $01 / 2004$ & 0,80 & $04 / 2008$ & 1,12 & $07 / 2012$ & 1,52 \\
\hline $11 / 1999$ & 2,53 & $02 / 2004$ & 1,08 & $05 / 2008$ & 1,88 & $08 / 2012$ & 1,29 \\
\hline $12 / 1999$ & 1,23 & $03 / 2004$ & 0,93 & $06 / 2008$ & 1,89 & $09 / 2012$ & 0,88 \\
\hline $01 / 2000$ & 1,02 & $04 / 2004$ & 1,15 & $07 / 2008$ & 1,12 & $10 / 2012$ & $-0,31$ \\
\hline $02 / 2000$ & 0,19 & $05 / 2004$ & 1,46 & $08 / 2008$ & $-0,38$ & $11 / 2012$ & 0,25 \\
\hline $03 / 2000$ & 0,18 & $06 / 2004$ & 1,29 & $09 / 2008$ & 0,36 & $12 / 2012$ & 0,66 \\
\hline $04 / 2000$ & 0,13 & $07 / 2004$ & 1,14 & $10 / 2008$ & 1,09 & $01 / 2013$ & 0,31 \\
\hline $05 / 2000$ & 0,67 & $08 / 2004$ & 1,31 & $11 / 2008$ & 0,07 & $02 / 2013$ & 0,20 \\
\hline $06 / 2000$ & 0,93 & 09/2004 & 0,48 & $12 / 2008$ & $-0,44$ & $03 / 2013$ & 0,31 \\
\hline $07 / 2000$ & 2,26 & $10 / 2004$ & 0,53 & $01 / 2009$ & 0,01 & $04 / 2013$ & $-0,06$ \\
\hline $08 / 2000$ & 1,82 & $11 / 2004$ & 0,82 & $02 / 2009$ & $-0,13$ & $05 / 2013$ & 0,32 \\
\hline $09 / 2000$ & 0,69 & $12 / 2004$ & 0,52 & $03 / 2009$ & $-0,84$ & $06 / 2013$ & 0,76 \\
\hline $10 / 2000$ & 0,37 & $01 / 2005$ & 0,33 & $04 / 2009$ & 0,04 & $07 / 2013$ & 0,14 \\
\hline $11 / 2000$ & 0,39 & $02 / 2005$ & 0,40 & $05 / 2009$ & 0,18 & $08 / 2013$ & 0,46 \\
\hline $12 / 2000$ & 0,76 & $03 / 2005$ & 0,99 & $06 / 2009$ & $-0,32$ & $09 / 2013$ & 1,36 \\
\hline $01 / 2001$ & 0,49 & $04 / 2005$ & 0,51 & $07 / 2009$ & $-0,64$ & $10 / 2013$ & 0,63 \\
\hline $02 / 2001$ & 0,34 & $05 / 2005$ & $-0,25$ & 08/2009 & 0,09 & $11 / 2013$ & 0,28 \\
\hline $03 / 2001$ & 0,80 & $06 / 2005$ & $-0,45$ & $09 / 2009$ & 0,25 & $12 / 2013$ & 0,69 \\
\hline $04 / 2001$ & 1,13 & $07 / 2005$ & $-0,40$ & $10 / 2009$ & $-0,04$ & $01 / 2014$ & 0,40 \\
\hline $05 / 2001$ & 0,44 & $08 / 2005$ & $-0,79$ & $11 / 2009$ & 0,07 & $02 / 2014$ & 0,85 \\
\hline $06 / 2001$ & 1,46 & $09 / 2005$ & $-0,13$ & $12 / 2009$ & $-0,11$ & $03 / 2014$ & 1,48 \\
\hline $07 / 2001$ & 1,62 & $10 / 2005$ & 0,63 & $01 / 2010$ & 1,01 & $04 / 2014$ & 0,45 \\
\hline $08 / 2001$ & 0,90 & $11 / 2005$ & 0,33 & $02 / 2010$ & 1,09 & $05 / 2014$ & $-0,45$ \\
\hline $09 / 2001$ & 0,38 & $12 / 2005$ & 0,07 & $03 / 2010$ & 0,63 & $06 / 2014$ & $-0,63$ \\
\hline $10 / 2001$ & 1,45 & $01 / 2006$ & 0,72 & $04 / 2010$ & 0,72 & $07 / 2014$ & $-0,55$ \\
\hline $11 / 2001$ & 0,76 & $02 / 2006$ & $-0,06$ & $05 / 2010$ & 1,57 & $08 / 2014$ & 0,06 \\
\hline $12 / 2001$ & 0,18 & $03 / 2006$ & $-0,45$ & $06 / 2010$ & 0,34 & $09 / 2014$ & 0,02 \\
\hline $01 / 2002$ & 0,19 & $04 / 2006$ & 0,02 & $07 / 2010$ & 0,22 & $10 / 2014$ & 0,59 \\
\hline $02 / 2002$ & 0,18 & $05 / 2006$ & 0,38 & $08 / 2010$ & 1,10 & $11 / 2014$ & 1,14 \\
\hline $03 / 2002$ & 0,11 & $06 / 2006$ & 0,67 & $09 / 2010$ & 1,10 & $12 / 2014$ & 0,38 \\
\hline $04 / 2002$ & 0,70 & $07 / 2006$ & 0,17 & $10 / 2010$ & 1,03 & $01 / 2015$ & 0,67 \\
\hline $05 / 2002$ & 1,11 & $08 / 2006$ & 0,41 & $11 / 2010$ & 1,58 & $02 / 2015$ & 0,53 \\
\hline $06 / 2002$ & 1,74 & $09 / 2006$ & 0,24 & $12 / 2010$ & 0,38 & $03 / 2015$ & 1,21 \\
\hline $07 / 2002$ & 2,05 & $10 / 2006$ & 0,81 & $01 / 2011$ & 0,98 & $04 / 2015$ & 0,92 \\
\hline $08 / 2002$ & 2,36 & $11 / 2006$ & 0,57 & $02 / 2011$ & 0,96 & $05 / 2015$ & 0,40 \\
\hline $09 / 2002$ & 2,64 & $12 / 2006$ & 0,26 & $03 / 2011$ & 0,61 & $06 / 2015$ & 0,68 \\
\hline $10 / 2002$ & 4,21 & $01 / 2007$ & 0,43 & $04 / 2011$ & 0,50 & $07 / 2015$ & 0,58 \\
\hline $11 / 2002$ & 5,84 & $02 / 2007$ & 0,23 & $05 / 2011$ & 0,01 & $08 / 2015$ & 0,40 \\
\hline $12 / 2002$ & 2,70 & $03 / 2007$ & 0,22 & $06 / 2011$ & $-0,13$ & $09 / 2015$ & 1,42 \\
\hline $01 / 2003$ & 2,17 & $04 / 2007$ & 0,14 & $07 / 2011$ & $-0,05$ & $10 / 2015$ & 1,76 \\
\hline $02 / 2003$ & 1,59 & $05 / 2007$ & 0,16 & $08 / 2011$ & 0,61 & $11 / 2015$ & 1,19 \\
\hline $03 / 2003$ & 1,66 & $06 / 2007$ & 0,26 & $09 / 2011$ & 0,75 & $12 / 2015$ & 0,44 \\
\hline
\end{tabular}

Nota: Fonte: Ipea data (2016).

Anexo 3. Taxa de Câmbio Comercial, Real/Dólar (Venda), no fim do período de 1999 a 2015.

\begin{tabular}{ll||ll||ll||ll}
\hline Mês/Ano & R\$ / US\$ & Mês/Ano & R\$ / US\$ & Mês/Ano & R\$ / US\$ & Mês/Ano & R\$ / US\$ \\
\hline $01 / 1999$ & 1,9832 & $04 / 2003$ & 2,8898 & $07 / 2007$ & 1,8776 & $10 / 2011$ & 1,6885 \\
$02 / 1999$ & 2,0648 & $05 / 2003$ & 2,9656 & $08 / 2007$ & 1,9620 & $11 / 2011$ & 1,8109
\end{tabular}


BRASILEIRA (1999-2015)

\begin{tabular}{|c|c|c|c|c|c|c|c|}
\hline 03/1999 & 1,7220 & $06 / 2003$ & 2,8720 & 09/2007 & 1,8389 & $12 / 2011$ & 1,8758 \\
\hline 04/1999 & 1,6607 & $07 / 2003$ & 2,9655 & $10 / 2007$ & 1,7440 & $01 / 2012$ & 1,7391 \\
\hline 05/1999 & 1,7240 & $08 / 2003$ & 2,9665 & $11 / 2007$ & 1,7837 & $02 / 2012$ & 1,7092 \\
\hline 06/1999 & 1,7695 & $09 / 2003$ & 2,9234 & $12 / 2007$ & 1,7713 & $03 / 2012$ & 1,8221 \\
\hline 07/1999 & 1,7892 & $10 / 2003$ & 2,8562 & $01 / 2008$ & 1,7603 & $04 / 2012$ & 1,8918 \\
\hline 08/1999 & 1,9159 & $11 / 2003$ & 2,9494 & $02 / 2008$ & 1,6833 & $05 / 2012$ & 2,0223 \\
\hline 09/1999 & 1,9223 & $12 / 2003$ & 2,8892 & $03 / 2008$ & 1,7491 & $06 / 2012$ & 2,0213 \\
\hline $10 / 1999$ & 1,9530 & $01 / 2004$ & 2,9409 & $04 / 2008$ & 1,6872 & $07 / 2012$ & 2,0499 \\
\hline $11 / 1999$ & 1,9227 & $02 / 2004$ & 2,9138 & $05 / 2008$ & 1,6294 & $08 / 2012$ & 2,0372 \\
\hline $12 / 1999$ & 1,7890 & $03 / 2004$ & 2,9086 & $06 / 2008$ & 1,5919 & 09/2012 & 2,0306 \\
\hline $01 / 2000$ & 1,8024 & $04 / 2004$ & 2,9447 & $07 / 2008$ & 1,5666 & $10 / 2012$ & 2,0313 \\
\hline $02 / 2000$ & 1,7685 & $05 / 2004$ & 3,1291 & $08 / 2008$ & 1,6344 & $11 / 2012$ & 2,1074 \\
\hline 03/2000 & 1,7473 & $06 / 2004$ & 3,1075 & $09 / 2008$ & 1,9143 & $12 / 2012$ & 2,0435 \\
\hline $04 / 2000$ & 1,8067 & $07 / 2004$ & 3,0268 & $10 / 2008$ & 2,1153 & $01 / 2013$ & 1,9883 \\
\hline $05 / 2000$ & 1,8266 & $08 / 2004$ & 2,9338 & $11 / 2008$ & 2,3331 & $02 / 2013$ & 1,9754 \\
\hline $06 / 2000$ & 1,8000 & 09/2004 & 2,8586 & $12 / 2008$ & 2,3370 & $03 / 2013$ & 2,0138 \\
\hline $07 / 2000$ & 1,7748 & $10 / 2004$ & 2,8565 & $01 / 2009$ & 2,3162 & $04 / 2013$ & 2,0017 \\
\hline $08 / 2000$ & 1,8234 & $11 / 2004$ & 2,7307 & $02 / 2009$ & 2,3784 & $05 / 2013$ & 2,1319 \\
\hline $09 / 2000$ & 1,8437 & $12 / 2004$ & 2,6544 & 03/2009 & 2,3152 & 06/2013 & 2,2156 \\
\hline $10 / 2000$ & 1,9090 & $01 / 2005$ & 2,6248 & $04 / 2009$ & 2,1783 & $07 / 2013$ & 2,2903 \\
\hline $11 / 2000$ & 1,9596 & $02 / 2005$ & 2,5950 & 05/2009 & 1,9730 & 08/2013 & 2,3725 \\
\hline $12 / 2000$ & 1,9554 & $03 / 2005$ & 2,6662 & $06 / 2009$ & 1,9516 & 09/2013 & 2,2300 \\
\hline $01 / 2001$ & 1,9711 & $04 / 2005$ & 2,5313 & 07/2009 & 1,8726 & $10 / 2013$ & 2,2026 \\
\hline $02 / 2001$ & 2,0452 & $05 / 2005$ & 2,4038 & 08/2009 & 1,8864 & $11 / 2013$ & 2,3249 \\
\hline 03/2001 & 2,1616 & $06 / 2005$ & 2,3504 & 09/2009 & 1,7781 & $12 / 2013$ & 2,3426 \\
\hline $04 / 2001$ & 2,1847 & $07 / 2005$ & 2,3905 & $10 / 2009$ & 1,7440 & $01 / 2014$ & 2,4263 \\
\hline $05 / 2001$ & 2,3600 & $08 / 2005$ & 2,3637 & $11 / 2009$ & 1,7505 & $02 / 2014$ & 2,3334 \\
\hline $06 / 2001$ & 2,3049 & 09/2005 & 2,2222 & $12 / 2009$ & 1,7412 & 03/2014 & 2,2630 \\
\hline $07 / 2001$ & 2,4313 & $10 / 2005$ & 2,2543 & $01 / 2010$ & 1,8748 & $04 / 2014$ & 2,2360 \\
\hline 08/2001 & 2,5517 & $11 / 2005$ & 2,2070 & $02 / 2010$ & 1,8110 & $05 / 2014$ & 2,2390 \\
\hline 09/2001 & 2,6713 & $12 / 2005$ & 2,3407 & $03 / 2010$ & 1,7810 & $06 / 2014$ & 2,2025 \\
\hline $10 / 2001$ & 2,7071 & $01 / 2006$ & 2,2160 & $04 / 2010$ & 1,7306 & 07/2014 & 2,2674 \\
\hline $11 / 2001$ & 2,5287 & $02 / 2006$ & 2,1355 & $05 / 2010$ & 1,8167 & 08/2014 & 2,2396 \\
\hline $12 / 2001$ & 2,3204 & $03 / 2006$ & 2,1724 & $06 / 2010$ & 1,8015 & 09/2014 & 2,4510 \\
\hline $01 / 2002$ & 2,4183 & $04 / 2006$ & 2,0892 & $07 / 2010$ & 1,7572 & $10 / 2014$ & 2,4442 \\
\hline $02 / 2002$ & 2,3482 & $05 / 2006$ & 2,3005 & $08 / 2010$ & 1,7560 & $11 / 2014$ & 2,5601 \\
\hline $03 / 2002$ & 2,3236 & $06 / 2006$ & 2,1643 & 09/2010 & 1,6942 & $12 / 2014$ & 2,6562 \\
\hline $04 / 2002$ & 2,3625 & $07 / 2006$ & 2,1762 & $10 / 2010$ & 1,7014 & $01 / 2015$ & 2,6623 \\
\hline $05 / 2002$ & 2,5220 & $08 / 2006$ & 2,138 & $11 / 2010$ & 1,7161 & $02 / 2015$ & 2,8782 \\
\hline $06 / 2002$ & 2,8444 & $09 / 2006$ & 2,1742 & $12 / 2010$ & 1,6662 & 03/2015 & 3,2080 \\
\hline $07 / 2002$ & 3,4285 & $10 / 2006$ & 2,1430 & $01 / 2011$ & 1,6734 & $04 / 2015$ & 2,9936 \\
\hline $08 / 2002$ & 3,0223 & $11 / 2006$ & 2,1668 & $02 / 2011$ & 1,6612 & $05 / 2015$ & 3,1788 \\
\hline $09 / 2002$ & 3,8949 & $12 / 2006$ & 2,1380 & $03 / 2011$ & 1,6287 & $06 / 2015$ & 3,1026 \\
\hline $10 / 2002$ & 3,6450 & $01 / 2007$ & 2,1247 & $04 / 2011$ & 1,5733 & $07 / 2015$ & 3,3940 \\
\hline $11 / 2002$ & 3,6365 & $02 / 2007$ & 2,1182 & $05 / 2011$ & 1,5799 & $08 / 2015$ & 3,6467 \\
\hline $12 / 2002$ & 3,5333 & $03 / 2007$ & 2,0504 & $06 / 2011$ & 1,5611 & 09/2015 & 3,9729 \\
\hline $01 / 2003$ & 3,5258 & $04 / 2007$ & 2,0339 & $07 / 2011$ & 1,5563 & $10 / 2015$ & 3,8589 \\
\hline $02 / 2003$ & 3,5632 & $05 / 2007$ & 1,9289 & 08/2011 & 1,5872 & $11 / 2015$ & 3,8506 \\
\hline $03 / 2003$ & 3,3531 & $06 / 2007$ & 1,9262 & 09/2011 & 1,8544 & $12 / 2015$ & 3,9048 \\
\hline
\end{tabular}

Fonte: Ipea data (2016).

Anexo 4. Taxa de Câmbio Nominal, Real/Dólar (Valor de Venda, Média), período de 1999 a 2015.

\begin{tabular}{ll||ll||ll||ll}
\hline Mês/Ano & R\$ / US\$ & Mês/Ano & R\$ / US\$ & Mês/Ano & R\$ / US\$ & Mês/Ano & R\$ / US\$ \\
\hline $01 / 1999$ & 1,50 & $04 / 2003$ & 3,12 & $07 / 2007$ & 1,88 & $10 / 2011$ & 1,77 \\
$02 / 1999$ & 1,91 & $05 / 2003$ & 2,96 & $08 / 2007$ & 1,97 & $11 / 2011$ & 1,79 \\
$03 / 1999$ & 1,90 & $06 / 2003$ & 2,88 & $09 / 2007$ & 1,90 & $12 / 2011$ & 1,84 \\
$04 / 1999$ & 1,69 & $07 / 2003$ & 2,88 & $10 / 2007$ & 1,80 & $01 / 2012$ & 1,79 \\
$05 / 1999$ & 1,68 & $08 / 2003$ & 3,00 & $11 / 2007$ & 1,77 & $02 / 2012$ & 1,72
\end{tabular}

REPAE, São Paulo, v. 7, n. 1, p. 03-20, jan./abr. 2021. ISSN: 2447-6129 
INFLUÊNCIA DA TAXA DE CÂMBIO SOBRE A INFLAÇÃO NA ECONOMIA BRASILEIRA (1999-2015)

\begin{tabular}{|c|c|c|c|c|c|c|c|}
\hline 06/1999 & 1,77 & $09 / 2003$ & 2,92 & $12 / 2007$ & 1,79 & $03 / 2012$ & 1,80 \\
\hline $07 / 1999$ & 1,80 & $10 / 2003$ & 2,86 & $01 / 2008$ & 1,77 & $04 / 2012$ & 1,85 \\
\hline 08/1999 & 1,88 & $11 / 2003$ & 2,91 & $02 / 2008$ & 1,73 & $05 / 2012$ & 1,99 \\
\hline 09/1999 & 1,90 & $12 / 2003$ & 2,93 & $03 / 2008$ & 1,71 & $06 / 2012$ & 2,05 \\
\hline $10 / 1999$ & 1,97 & $01 / 2004$ & 2,85 & $04 / 2008$ & 1,69 & $07 / 2012$ & 2,03 \\
\hline $11 / 1999$ & 1,93 & $02 / 2004$ & 2,93 & $05 / 2008$ & 1,66 & $08 / 2012$ & 2,03 \\
\hline $12 / 1999$ & 1,84 & $03 / 2004$ & 2,91 & $06 / 2008$ & 1,62 & $09 / 2012$ & 2,03 \\
\hline $01 / 2000$ & 1,80 & $04 / 2004$ & 2,91 & $07 / 2008$ & 1,59 & $10 / 2012$ & 2,03 \\
\hline $02 / 2000$ & 1,78 & $05 / 2004$ & 3,10 & $08 / 2008$ & 1,61 & $11 / 2012$ & 2,07 \\
\hline $03 / 2000$ & 1,74 & $06 / 2004$ & 3,13 & $09 / 2008$ & 1,80 & $12 / 2012$ & 2,08 \\
\hline $04 / 2000$ & 1,77 & $07 / 2004$ & 3,04 & $10 / 2008$ & 2,17 & $01 / 2013$ & 2,03 \\
\hline $05 / 2000$ & 1,83 & $08 / 2004$ & 3,00 & $11 / 2008$ & 2,27 & $02 / 2013$ & 1,97 \\
\hline $06 / 2000$ & 1,81 & 09/2004 & 2,89 & $12 / 2008$ & 2,39 & $03 / 2013$ & 1,98 \\
\hline $07 / 2000$ & 1,80 & $10 / 2004$ & 2,85 & $01 / 2009$ & 2,31 & $04 / 2013$ & 2,00 \\
\hline $08 / 2000$ & 1,81 & $11 / 2004$ & 2,79 & $02 / 2009$ & 2,31 & $05 / 2013$ & 2,03 \\
\hline $09 / 2000$ & 1,84 & $12 / 2004$ & 2,72 & $03 / 2009$ & 2,31 & $06 / 2013$ & 2,17 \\
\hline $10 / 2000$ & 1,88 & $01 / 2005$ & 2,69 & $04 / 2009$ & 2,21 & $07 / 2013$ & 2,25 \\
\hline $11 / 2000$ & 1,95 & $02 / 2005$ & 2,60 & $05 / 2009$ & 2,06 & $08 / 2013$ & 2,34 \\
\hline $12 / 2000$ & 1,96 & $03 / 2005$ & 2,70 & $06 / 2009$ & 1,96 & $09 / 2013$ & 2,27 \\
\hline $01 / 2001$ & 1,95 & $04 / 2005$ & 2,58 & $07 / 2009$ & 1,93 & $10 / 2013$ & 2,19 \\
\hline $02 / 2001$ & 2,00 & $05 / 2005$ & 2,45 & $08 / 2009$ & 1,85 & $11 / 2013$ & 2,30 \\
\hline 03/2001 & 2,09 & $06 / 2005$ & 2,41 & $09 / 2009$ & 1,82 & $12 / 2013$ & 2,35 \\
\hline $04 / 2001$ & 2,19 & $07 / 2005$ & 2,37 & $10 / 2009$ & 1,74 & $01 / 2014$ & 2,38 \\
\hline $05 / 2001$ & 2,30 & $08 / 2005$ & 2,36 & $11 / 2009$ & 1,73 & $02 / 2014$ & 2,38 \\
\hline $06 / 2001$ & 2,38 & $09 / 2005$ & 2,29 & $12 / 2009$ & 1,75 & $03 / 2014$ & 2,33 \\
\hline $07 / 2001$ & 2,47 & $10 / 2005$ & 2,26 & $01 / 2010$ & 1,78 & $04 / 2014$ & 2,23 \\
\hline 08/2001 & 2,51 & $11 / 2005$ & 2,21 & $02 / 2010$ & 1,84 & $05 / 2014$ & 2,22 \\
\hline $09 / 2001$ & 2,67 & $12 / 2005$ & 2,29 & $03 / 2010$ & 1,79 & $06 / 2014$ & 2,24 \\
\hline $10 / 2001$ & 2,74 & $01 / 2006$ & 2,27 & $04 / 2010$ & 1,76 & $07 / 2014$ & 2,22 \\
\hline $11 / 2001$ & 2,54 & $02 / 2006$ & 2,16 & $05 / 2010$ & 1,81 & $08 / 2014$ & 2,27 \\
\hline $12 / 2001$ & 2,36 & $03 / 2006$ & 2,15 & $06 / 2010$ & 1,81 & $09 / 2014$ & 2,33 \\
\hline $01 / 2002$ & 2,38 & $04 / 2006$ & 2,13 & $07 / 2010$ & 1,77 & $10 / 2014$ & 2,45 \\
\hline $02 / 2002$ & 2,42 & $05 / 2006$ & 2,18 & $08 / 2010$ & 1,76 & $11 / 2014$ & 2,55 \\
\hline $03 / 2002$ & 2,35 & $06 / 2006$ & 2,25 & $09 / 2010$ & 1,72 & $12 / 2014$ & 2,64 \\
\hline $04 / 2002$ & 2,32 & $07 / 2006$ & 2,19 & $10 / 2010$ & 1,69 & $01 / 2015$ & 2,63 \\
\hline $05 / 2002$ & 2,48 & $08 / 2006$ & 2,16 & $11 / 2010$ & 1,71 & $02 / 2015$ & 2,82 \\
\hline $06 / 2002$ & 2,71 & $09 / 2006$ & 2,17 & $12 / 2010$ & 1,69 & $03 / 2015$ & 3,14 \\
\hline $07 / 2002$ & 2,93 & $10 / 2006$ & 2,15 & $01 / 2011$ & 1,67 & $04 / 2015$ & 3,04 \\
\hline 08/2002 & 3,11 & $11 / 2006$ & 2,16 & $02 / 2011$ & 1,67 & $05 / 2015$ & 3,06 \\
\hline 09/2002 & 3,34 & $12 / 2006$ & 2,15 & $03 / 2011$ & 1,66 & $06 / 2015$ & 3,11 \\
\hline $10 / 2002$ & 3,81 & $01 / 2007$ & 2,14 & $04 / 2011$ & 1,59 & $07 / 2015$ & 3,22 \\
\hline $11 / 2002$ & 3,58 & $02 / 2007$ & 2,10 & $05 / 2011$ & 1,61 & $08 / 2015$ & 3,51 \\
\hline $12 / 2002$ & 3,63 & $03 / 2007$ & 2,09 & $06 / 2011$ & 1,59 & $09 / 2015$ & 3,91 \\
\hline $01 / 2003$ & 3,44 & $04 / 2007$ & 2,03 & $07 / 2011$ & 1,56 & $10 / 2015$ & 3,88 \\
\hline $02 / 2003$ & 3,59 & $05 / 2007$ & 1,98 & $08 / 2011$ & 1,60 & $11 / 2015$ & 3,78 \\
\hline $03 / 2003$ & 3,45 & $06 / 2007$ & 1,93 & $09 / 2011$ & 1,75 & $12 / 2015$ & 3,87 \\
\hline
\end{tabular}

Fonte: Ipea data (2016). 